\title{
The Intra-Annual Intrinsic Water Use Efficiency Dynamics Based on an Improved Model
}

\section{Xiaojin Bing}

Fujian Normal University Cangshan Campus https://orcid.org/0000-0002-2140-8385

Keyan Fang ( $\nabla$ kujanfang@gmail.com )

Fujian Normal University Cangshan Campus https://orcid.org/0000-0002-0207-0112

\section{Xiaoying Gong}

Fujian Normal University Cangshan Campus

\section{Wenzhi Wang}

Fujian Normal University Cangshan Campus

\section{Chenxi Xu}

Institute of Geology and Geophysics Chinese Academy of Sciences

Maihe Li

Tree Physiology Division, Swiss Federal Research Institute WSL

\section{Chaoyue Ruan}

Fujian Normal University Cangshan Campus

\section{Weiting Ma}

Fujian Normal University Cangshan Campus

\section{Yingjun Li}

Taiyuan Normal University

\section{Feifei Zhou}

Fujian Normal University Cangshan Campus

\section{Research Article}

Keywords: Intrinsic Water, Efficiency, Model, carbon isotope, fractionation value, plants

Posted Date: November 29th, 2021

DOI: https://doi.org/10.21203/rs.3.rs-1060472/v1

License: (9) This work is licensed under a Creative Commons Attribution 4.0 International License. Read Full License 
1 The intra-annual intrinsic water use efficiency dynamics based on an

2 improved model

3

4

5

6

7

8

9

\section{Abstract}

The carbon isotope fractionation value $(\Delta)$ has been widely used to infer the intrinsic water use efficiency (iWUE) of C3 plants. Currently, the most commonly used iWUE method (expressed as iWUE tra ) in tree rings assumes that the mesophyll conductance in plants is infinite. However, many observation-based studies have pointed out that such an assumption leads to overestimating the impact of carbon dioxide (CO 2 ) on intrinsic water use efficiency in plants. In this study, a constant g s /g m ratio (0.79) was introduced for calculating iWUE (expressedas iWUE mes ). We applied this iWUE mes model to our newly developed intra-annual (10 samples per ring) $\Delta 13 \mathrm{C}$ chronology of Cryptomeria fortunei tree for 1965-2017 at $\mathrm{Gu}$ Mountain Area and our annual $\Delta 13 \mathrm{C}$ chronology of Pinus massoniana tree for 1865-2014 at Niumulin Natural Reserve in southeast China. Using dendrochronology techniques, our analysis revealed that the current iWUE tra model overestimates the iWUE values by approximately 2 times and that the iWUE value of trees inferred from iWUE mes modelling decreased significantly in summer-autumn time, which may indicate that alternative factors play a role in limiting the degree of iWUE improvement under the drought-stressed forest in southeast China.

\section{Introduction}


Stable isotopes in tree rings could provide palaeoclimate reconstructions with perfect annual resolution and statistically defined confidence limits to study a variety of natural phenomena or events(G, D, Farquhar et al., 1989; Danny McCarroll, 2004; J Huang et al., 2007; Schnyder et al.,2012; Lucas C. R. Silva et al., 2013; X Liu et al., 2014; Millicent Smith et al., 2016). For example, the methods involving the stable carbon isotope ratios in tree rings often used to reconstruct past climate and environmental changes(G, D, Farquhar et al., 1989; Ehleringer et al., 1993; Franks et al., 2013) and to study the physiological and ecological changes of trees caused by past climate regimes(Tei et al., 2014).

Intrinsic water use efficiency (iWUE) in plants is a physiological efficiency that represents the ratio of net assimilation (A) and stomatal conductance to water vapor $\left(g_{w}\right)$. It reflects the relationship between plant water consumption and dry matter production, therefore is a comprehensive physiological and ecological index for evaluating the suitability of plant growth (Danny McCarroll, 2004; Schweingruber et al., 2004). The increase in atmospheric $\mathrm{CO}_{2}$ levels can theoretically increase the intercellular $\mathrm{CO}_{2}$ concentration of plant leaves, and therefore, can promote the photosynthesis of plants, resulting in a "fertilization effect"(J Huang et al., 2007; Ze'ev Gedalof et al., 2010). In addition, this increase in atmospheric $\mathrm{CO}_{2}$ concentration also causes a decrease in stomatal conductance(I. C. Prentice et al., 2009; Lucas C. R. Silva et al., 2013). The resulting ratio of the net photosynthetic rate of the plant to the stomatal conductance, i.e. iWUE, shows an increasing trend, which 
can alleviate drought to a certain extent and is beneficial to the growth of plants in arid and semi-arid areas (Leavitt et al., 1993; Todd E. Dawson et al., 2002; Andrea Scartazza et al., 2014; X Liu et al., 2014; Pei-Li Fu et al., 2016).

The current iWUE model based on stable isotopes of tree rings as proposed by Farquhar et al.(G, D, Farquhar et al., 1989), is calculated as follows: iWUE $=\mathrm{A} / \mathrm{g}_{\mathrm{w}}$ $=C_{a}\left(1-C_{a} / C_{i}\right) \times 0.625$ (where $C_{a}$ and $C_{i}$ are the $\mathrm{CO}_{2}$ concentrations outside and inside the stomata of plant leaves, respectively. $\mathrm{A}$ is the assimilation rate of $\mathrm{CO}_{2}$ by plant leaves, and $g_{w}$ is the stomatal conductance of plant leaves). This model has been widely used to infer iWUE based on the $\delta^{13} \mathrm{C}$ values in climate archives, such as pasture(Schnyder et al., 2012), tree rings(Franks et al., 2013; Zuidema et al., 2015), or animal tissue(INÊS C. R. BARBOSA et al., 2010). Compared with the instantaneous iWUE measured by gas exchange, the biomass-based $\Delta$ provides a time-integrated iWUE and enables time series analysis from days to thousands of years (Schweingruber et al., 2004; Mcelwain et al., 2019; Adams et al., 2020).

However, some researchers consider that the traditional model's biased prediction of iWUE limits its application to qualitative assessment(Medrano et al., 2010). The main limitation of using the traditional iWUE model ( $\mathrm{iWUE}_{\text {tra }}$ ) is the simplification of the mesophyll conductance $\left(g_{m}\right.$, the diffusion conductance of $\mathrm{CO}_{2}$ from the intercellular space to the carboxylation site). Theoretically, this assumption leads to overestimating the iWUE(W Ma et al., 2020), as $g_{m}$ is not conservatively high(Medrano et al., 2010). 
In other words, it may not be appropriate to apply an infinite or species-specific constant $g_{m}$ in the iWUE model. In general, the wide application of the ${ }^{12} \mathrm{C} /{ }^{13} \mathrm{C}$ isotope fractionation method in calculating the iWUE usually ignores the influence of the mesophyll conductance, either because of technical reasons (difficult to measure mesophyll conductance), or because its impact is assumed to be relatively small (assuming infinite $g_{m}$ exists in iWUE tra $_{\text {(B) }}$ (Berry et al., 2008; Franks et al., 2013; Zsofa R. Stangl et al., 2019).

In southeast subtropical China, the Western Pacific Subtropical High (WPSH) causes high temperatures and low rainfall during the summer-autumn time(Yong Hua et al., 2013). Li et al. (2017) suggested that the contribution of iWUE to the tree growth in southeast China is not significant in most periods(Li et al., 2017). The growth promotion of the increased iWUE on tree growth in southeast China was later determined by Li et al. (2019) to not compensate for the growth limitation caused by drought(Y Li et al., 2019). The above results were all based on analyses of the entire rings, and $\mathrm{iWUE}_{\text {tra }}$ modelling has shown similar conclusions. In such models, the growth was not stimulated, but the iWUE increased significantly, and the " $\mathrm{CO}_{2}$ fertilization effect" was observed. This shows that atmospheric $\mathrm{CO}_{2}$ concentration on the annual scale is probably not the only factor that affects the iWUE of trees in different regions. Yet, the cause and influencing factors of the iWUE changes during the growing season are still unknown. 
Here, we hypothesize that, because of higher climate variability and more stable $\mathrm{CO}_{2}$ concentration, the intra-annual scale can better reflect how the iWUE changes and what affects it. To test this, a higher-resolution intra-annual tree-ring $\delta^{13} \mathrm{C}$ chronology from 1965 to 2017 at Gu Mountain Area (GM), combined with our tree-ring $\delta^{13} \mathrm{C}$ data from Niumulin Natural Reserve (NML) that has previously been published(Li et al., 2017), were established. This study aims to: 1) calculate the iWUE of trees at GM using the higher-resolution iWUE $_{\text {mes }}$ model that includes the $g_{m}$ effect; 2) show the characteristics of iWUE on the intra-annual (representing the drastic changes of climate variables from winter to summer) and annual scales (representing the longer inter-annual change of $\mathrm{CO}_{2}$ concentration) with two different models; and 3) further disentangle the relationship between $C_{a}$, climate, and iWUE under drought-stressed conditions.

\section{Data and methods}

\subsection{Sampling site and climate data}

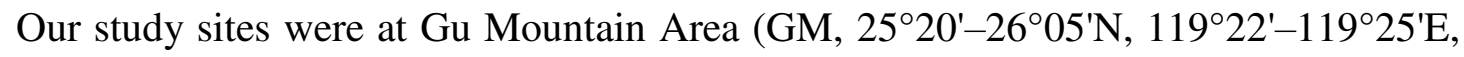
about 8 kilometers away from the downtown area of Fuzhou City) and Niumulin Natural Reserve (NML, $25^{\circ} 23^{\prime}-25^{\circ} 25^{\prime} \mathrm{N}, 117^{\circ} 55^{\prime}-117^{\circ} 57^{\prime} \mathrm{E}$, data has been published) (Li et al., 2017)(Fig. 1). GM is located in the transition zone from the south subtropical zone to the mid-subtropical zone. It is warm and humid with abundant rainfall throughout the year(Zhang et al., 2009). According to the nearest Fuzhou meteorological observation data from 1953 to 2019, the average annual precipitation 
111

112

is $1366 \mathrm{~mm}$, and the average annual temperature is $19.9^{\circ} \mathrm{C}$. Pinus massoniana tree and Cryptomeria fortunei tree are constructive species within the well-protected forests. In July of 2018, a total of 186 tree cores were collected from a sample of 87 living Cryptomeria fortunei trees with a mean age of 75 years at GM. These were collected using $5 \mathrm{~mm}$ diameter increment borers to extract 2-3 cores from each tree at a height of $1.3 \mathrm{~m}$. The climate data of GM and NML sampling sites are obtained from the nearby Fuzhou meteorological station and Yong'an meteorological station, respectively.

In order to obtain more real-time data on intercellular $\mathrm{CO}_{2}$ concentration during the growing season for trees, we downloaded the monthly global atmospheric $\mathrm{CO}_{2}$ concentration observation data from the Mauna Loa Observatory in Hawaii (https://scrippsco2.ucsd.edu/data/atmospheric_co2.html), USA, for the period 1958-2017. Furthermore, we calculated additional variables (including meteorological variables and atmospheric $\mathrm{CO}_{2}$ concentration) corresponding to 10 intra-annual periods based on the length of the tree growing season (April-October) at GM.

\subsection{Experimental treatment}

\subsubsection{Separation of high-resolution intra-annual tree rings}

Cores were air dried and hand-sanded with sand paper up to 1200 grit. Visual cross-matching and skeleton plots were used to assign a calendar date to each 
$\operatorname{ring}($ Stokes \& Smiley, 1968). Using the results from the COFECHA and the moving correlation coefficient between a single sample core and the master sequence, we selected a total of 6 Cryptomeria fortunei tree cores with higher correlation coefficients, longer sequences, relatively wide annual rings, no obvious differences in growth, and with the fewer missing rings. These were used to carry out high-resolution experiments of stable carbon isotopes in tree rings. In this study, the average ring width of Cryptomeria fortunei tree we used is $5 \mathrm{~mm}$. In order to obtain more accurate and high-resolution intra-annual sub-samples, we measured the width of each annual ring of each tree core in advance and divided it into 10 sub-samples equally. We then cut off each sub-ring using a dissecting scalpel according to the calculated width value.

\subsubsection{Chemical treatment and stable isotope measurement}

With a slight improvement on the method proposed by Liu Xiaohong( X LIU et al., 2007), we followed the standard method(Leavitt et al., 2008) to mix each intra-annual sub-sample to extract $\alpha$-cellulose from the wood. We used custom-made hourglass tubes to realize the full reaction of the chemistry reagent, thereby speeding up the further steps and saving experimental time.

We packed $0.08-0.12 \mathrm{mg}$ of $\alpha$-cellulose in tin capsules for stable isotope measurement using the Flash Elemental Analyzer (Flash 2000) coupled with a Thermo Scientific MAT 253 (Thermo Electron Corporation, Bremen, Germany). 
155

156 (standard sample, $\delta^{13} \mathrm{C}=-22.43 \%$ ) was used to calibrate the values of $\delta^{13} \mathrm{C}$ gained

157 from tree-ring $\alpha$-cellulose. For convenience, the rate of stable carbon isotope $\left({ }^{13} \mathrm{C} /{ }^{12} \mathrm{C}\right)$

158 was defined in delta $(\delta)$ according to the Vienna Pee Dee Belemnite (VPDB)

159 standard(Leavitt \& GEOL, 2008), in parts per thousand (\%o)):

160

161

162

163

164

165

166

167

168

169

170

171

172 173 2014).

174

175

$\delta^{13} \mathrm{C}=\left[\left(R_{\text {sampld }} / R_{\text {standard }}\right)-1\right] \times 1000$

where $\mathrm{R}_{\text {sample }}$ and $\mathrm{R}_{\text {standard }}$ represent the ${ }^{13} \mathrm{C} /{ }^{12} \mathrm{C}$ ratios of tree-ring $\alpha$-cellulose sample and VPDB standard, respectively. Our isotopic measurements were stable with a low standard deviation of $0.15 \%$.

Isotopic discrimination between atmospheric $\mathrm{CO}_{2}$ carbon and plant carbon $(\Delta$; see Farquhar \& Richards, 1984) in C3 plants is a result of the preferential use of ${ }^{12} \mathrm{C}$ over ${ }^{13} \mathrm{C}$ during photosynthesis, and it is defined as follows:

$\Delta^{13} C=\left(\delta^{13} C_{a}-\delta^{13} C_{p}\right) /\left(1+\delta^{13} C_{p} / 1000\right)$

where $\Delta^{13} \mathrm{C}$ is the stable carbon isotope discrimination, $\delta^{13} \mathrm{C}_{\mathrm{a}}$ and $\delta^{13} \mathrm{C}_{\mathrm{p}}$ are the stable carbon isotopic ratios $\left({ }^{13} \mathrm{C} /{ }^{12} \mathrm{C}\right)$ of ambient air and plant cellulose, $\delta^{13} \mathrm{C}_{\mathrm{a}}$ represents a constant value of $-6.4 \%$ before 1850 (Millicent Smith et al., 2016), and the $\delta^{13} C_{a}$ value after 1850 is calculated based on ice core bubbles and monitoring data(X Liu et al.,

\subsubsection{Stable carbon isotopic analysis}

The field tree growth monitoring research conducted at the GM study site shows that 
the cambium cells of Cryptomeria fortunei begin to expand around April, and the entire lignification process ends around November. Combined with dendrometer data, we determined that the entire growing season of Cryptomeria fortunei in the study site is approximately from April 6th to November 5th each year, of which June 15th is the dividing line between earlywood and latewood. To find this, we used the method developed by Berkelhammer and Stott(Max Berkelhammer et al., 2009), combined with the observed growth dates of the earlywood and latewood of the Cryptomeria fortunei. We then used the following equation to assign dates to the 10 sub-samples in each ring and recorded the dates of these samples' stable carbon isotope values (Table 1):

$$
\text { Date }=s_{i}+\left(n_{s} / n_{t}\right) \cdot e_{s}
$$

where $s_{i}$ is the date of the start of growing season, which is taken as April 6 and remains unchanged; $e_{s}$ is the length of the earlywood growing season (70 days for earlywood; 203 days for latewood); $n_{s}$ is the sample number; and $n_{t}$ is the total number of sub-samples in each ring.

\subsection{Intrinsic water use efficiency (iWUE)}

\subsubsection{Traditional intrinsic water use efficiency model (iWUE tra $_{\text {) }}$ )}

We assumed that the values of $C_{a}$ and $\delta^{13} \mathrm{C}_{\mathrm{a}}$ at the sampling site are equal to the atmospheric $\mathrm{CO}_{2}$ concentration and its carbon isotope, respectively, as previous studies have revealed ( $\mathrm{Li}$ et al., 2017; Y Li et al., 2019). The discrimination of atmospheric $\mathrm{CO}_{2}$ by plants (the fractionation of carbon isotopes $\left(\Delta^{13} \mathrm{C}\right)$ ) is an 
199

important indicator of the intrinsic water use efficiency of plants. After conversion, the following formula is obtained(G, D, Farquhar et al., 1989):

$$
i W U E=\frac{A}{g_{w}}=\frac{C_{a}-C_{i}}{1.6}=\frac{C_{a}\left(1-C_{i} / C_{a}\right)}{1.6}
$$

where $A$ is the net photosynthetic rate of the plant; $g_{w}$ is stomatal conductance to water vapor; $C_{a}$ and $C_{i}$ are the $\mathrm{CO}_{2}$ concentration outside and inside the stomata of plant leaves, respectively; and the value of $C_{i} / C_{a}$ in the formula can be calculated using Eq.

5(G, D, Farquhar et al., 1989):

$$
\frac{C_{i}}{C_{a}}=\frac{\Delta^{13} C-a}{b-a}
$$

where $a(4.4 \%)$ represents the isotope discrimination of atmospheric $\mathrm{CO}_{2}$ entering in the intercellular space and $b(27 \%)$ represents the isotope discrimination value due to the carboxylation(G, D, Farquhar et al., 1989).

Therefore, based on the linear formula between $\Delta^{13} \mathrm{C}$ and $C_{a}$, the traditional model of iWUE is obtained(JAMES R. EHLERINGER et al., 1995):

$$
i W U E_{\text {tra }}=\frac{C_{a}\left(1-C_{i} / C_{a}\right)}{1.6}=\frac{C_{a}\left(b-\Delta^{13} C\right)}{1.6(b-a)}=\frac{C_{a}}{1.6} \times \frac{b-\Delta^{13} C}{b-a}
$$

where the subscript "tra" represents the traditional simple intrinsic water use efficiency model.

\subsubsection{Improved intrinsic water use efficiency model (iWUE mes $)$}

Here, we used an improved model of iWUE that includes the effect of $g_{m}$ (denoted as iWUE $_{\text {mes }}$ )(Wei Ting Ma, 2020). 
$220 i W U E_{\text {mes }}=\frac{A}{g_{w}}=\frac{C_{a}}{1.6} \cdot \frac{b^{\prime}-\Delta-f^{\prime} \frac{\Gamma^{*}}{C_{a}}}{b^{\prime}-a_{s}+\frac{g_{s c}}{g_{m}} \cdot\left(b^{\prime}-a_{m}\right)}$

221 where the subscript "mes" indicates that this expression accounts for mesophyll

222 conductance effects; $C_{a}$ is the $\mathrm{CO}_{2}$ mole fraction in the atmosphere; $a_{m}(1.8 \%)$ is the

223 fractionation associated with $\mathrm{CO}_{2}$ dissolution and diffusion in the mesophyll; $\Gamma^{*}$ is the

$224 \mathrm{CO}_{2}$ compensation point in the absence of mitochondrial respiration; $b^{\prime}(29 \%)$ and $f^{\prime}$

$225(11 \%)$ represent the fractionations due to carboxylation and photorespiration, 226 respectively; $a_{s}\left(4.4 \%\right.$ ) is the ${ }^{12} \mathrm{C} /{ }^{13} \mathrm{C}$ fractionations during $\mathrm{CO}_{2}$ diffusion through the 227 stomata; an error that can be corrected by using a constant $g_{s c} / g_{m}$ is a constant ratio 228 (0.79) based on measurements of a wide range of plant species from different 229 functional groups (including grasses and herbaceous legumes), in moist and dry 230 conditions(W Ma et al.,2020).

According to the iWUE model, the intercellular $\mathrm{CO}_{2}$ concentration value (Tei et al.)

233 in the trees can be inferred using Eq. 8:

\section{Results}

\subsection{Tree-ring width chronology and climate-growth relationship}

The annual tree-ring width variability of Cryptomeria fortunei at the GM site mainly showed three stages: a downward trend of width from 1965 to 1985, an upward trend 
from 2001 to 2017. In general, the tree-ring width across the whole period from 1965 to 2017 showed a "W-shaped" trend (Fig. S1).

The standard chronology of tree-ring width (STD) at the GM site showed the most significant negative correlation with temperature and sunshine hours in the previous July, the current June, and the current June to September, respectively. Meanwhile, the STD at the GM site showed the most significant positive correlation with relative humidity in the current June, July, October, and the current June to September (Fig. 2).

The intra-annual tree-ring width of Cryptomeria fortunei at the GM site fluctuated: before 1985, the width was relatively narrow; then it increased rapidly and peaked in 1997; the width then gradually decreased between 1998 and 2007; after which, there followed a slowly increasing trend from 2008 to 2017 (Fig. S2a). After eliminating age-related growth trends (Fig. S2b), we found the STD to be relatively stable from 1965 to 2017, with a weak inter-decadal variability (Fig. S2b). The inter-decadal variability of STD increased steadily with time after 1980, reached a peak value in 2000, then declined slightly and increased again from 2010 to 2017, reaching a high value again in 2017.

\subsection{Chronology of tree-ring $\Delta^{13} \mathrm{C}$}

For the study period of 1965-2017, we observed that the intra-annual average values 
of both tree-ring $\delta^{13} \mathrm{C}$ and $\Delta^{13} \mathrm{C}$ have clear seasonal patterns (Fig. S3). Overall, the intra-annual tree-ring $\delta^{13} \mathrm{C}$ values decreased from April 18-April 29 to October 01-November 05 (-0.051), reaching the maximum during October 01-November 05 (Fig. S3). In addition, the intra-annual tree-ring $\Delta^{13} \mathrm{C}$ is relatively stable $(-0.24 \%)$, reaching the minimum during April 06-April 17 and the maximum during April 18-April 29.

\subsection{The relationship between tree-ring $\Delta^{13} \mathrm{C}$ and climate variables at} GM study site

We found that the intra-annual tree-ring $\Delta^{13} \mathrm{C}$ at the GM site from 1965 to 2017 was positively correlated with relative air humidity from April 18 to September 30 $(\mathrm{P}>0.05)$ and significantly correlated with the humidity for October 01-November 05 $(\mathrm{r}=0.351, \mathrm{p}<0.001)$. The intra-annual tree-ring $\Delta^{13} \mathrm{C}$ was significantly positively correlated with sunshine hours for April 06-April 17 and August 26-September 30. A significant negative correlation between the intra-annual tree-ring $\Delta^{13} \mathrm{C}$ and the temperature were observed during the summer time (i.e., June 15-July 20, July 21-August 25, and October 01-November 05) (Fig. 4).

\subsection{The iWUE mes $_{\text {and }}$ iWUE $E_{\text {tra }}$ at study sites}

At GM site, both the $\mathrm{iWUE}_{\mathrm{mes}}$ (the slope of linear regression being: $0.04, \mathrm{R}^{2}=0.83, \mathrm{p}$ $<0.001$ ) and iWUE $_{\text {tra }}$ (the slope of linear regression being: $0.08, \mathrm{R}^{2}=0.83, \mathrm{p}<0.001$ ) chronologies showed significant increasing trends during the period from 1965 to 
2017 (Fig. 5a). At the NML site, both the iWUE $_{\text {mes }}$ (the slope of linear regression being: $0.12, \mathrm{R}^{2}=0.84, \mathrm{p}<0.001$ ) and $\mathrm{iWUE}_{\text {tra }}$ (the slope of linear regression being: $\left.0.23, \mathrm{R}^{2}=0.83, \mathrm{p}<0.001\right)$ chronologies, calculated with tree-ring $\Delta^{13} \mathrm{C}$ series, showed significant increasing trends during the period from 1865 to 2014 (Fig. 5b).

At the GM site, the ratios of $\mathrm{iWUE}_{\text {tra }}$ to $\mathrm{iWUE}_{\text {mes }}$ were $1.88,1.89,1.90,1.91,1.92$, $1.93,1.96,1.96,1.94$, and 1.91 during the 10 periods studied on the intra-annual scale, which gradually increased from April 06-April 17 to July 21-August 25 (4.6\%) and peaked during July 21-August 25. At the NML study site, the average ratio of iWUE $_{\text {tra }}$ to iWUE $_{\text {mes }}$ was 2.05 on the inter-annual scale, which decreased from 2.08 in 1965 to 1.99 in 2014.

\subsection{The intra-annual iWUE $\mathrm{Emes}_{\text {and }}$ iWUE $\mathrm{E}_{\text {tra }}$ at GM study sites}

The trend of the intra-annual iWUE values during April 18-May 22 at GM calculated from Eq.5 and Eq.6 is significantly consistent (the rate of decline for $\mathrm{iWUE}_{\text {tra }}$ and $\mathrm{iWUE}_{\mathrm{mes}}$ are $2 \%$ and $1 \%$, respectively). The notable difference between $\mathrm{iWUE}_{\text {tra }}(\mathrm{y}=$ $\left.-0.5 \times x^{2}+1.57 x+117.74, R^{2}=1\right)$ and $\operatorname{iWUE}_{\text {mes }}\left(y=0.115 \times x^{2}-0.505 x+61.17, R^{2}\right.$ = 1) appears during June 15-September 30 (i.e., drought-stressed condition in summer and autumn drawn above) (Fig. 6).

For $\mathrm{iWUE}_{\mathrm{mes}}$ during June 15-September 30, the values reduced from $60.78 \mu \mathrm{mol}$ $\mathrm{mol}^{-1}$ (June 15-July 20) to $60.62 \mu \mathrm{mol} \mathrm{mol}^{-1}$ (July 21-August 25) (reduced by 
approximately $0.3 \%$ ) and then increased to $60.69 \mu \mathrm{mol} \mathrm{mol}^{-1}$ (August 26-September 30) (increased by approximately $0.1 \%$ ). During this time, the minimum iWUE $\mathrm{E}_{\text {mes }}$ value occurred during July 21-August 25 (Fig. 6).

Meanwhile, for iWUE $\mathrm{tra}_{\text {tra }}$ during June 15-September 30, the value dropped by approximately $0.06 \%$ from June $15-$ July 20 to July 21 -August 25 and then increased by approximately $0.78 \%$ from July 21 -August 25 to August 26-September 30. Here,

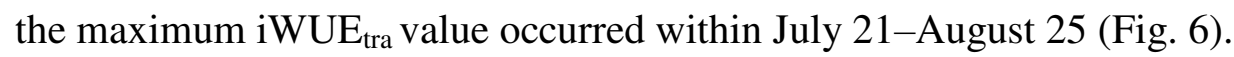

\subsection{The relationship between iWUE chronologies and climate}

\section{variables}

Taken as a whole, the relative importance of each climate variables to the intra-annual $\mathrm{iWUE}_{\mathrm{mes}}$ and $\mathrm{iWUE}_{\text {tra }}$ values for the period of 1965-2017 is assessed on the basis of stepwise regression results with relaimpo package in $\mathrm{R}$ (Fig.7). Referring to $\mathrm{R}^{2}$ and to the number of retained series (with $\mathrm{p}<0.1$ ), the climate factor that contributes the most to the iWUE in trees regardless of the model is relative humidity, followed by sunshine hours and temperature. Meanwhile, the least contributing climate factor is precipitation. Specifically, during April 06-April 17, the difference in the contribution of temperature, precipitation, and sunshine hours to the iWUE calculated using the two iWUE models was the greatest.

\section{Discussion}




\subsection{Summer drought stress and tree growth}

The correlation analysis revealed a drought stress during summer on tree growth at GM (Fig. 2). The stressed growth patterns caused by such summer drought have also been revealed in nearby regions of eastern Fujian province. For example, Li et al.(Li, 2017) and Li et al.(Yingjun Li, 2019) revealed that the growth of Pinus massoniana were mainly controlled by the July-September precipitation in the eastern region of the Fujian province. Chen et al.(Dan Chen et al.,, 2016) also demonstrated that the July-August precipitation is the major limiting factor for the tree-ring growth of Pinus taiwanensis on Daiyun Mountain of the Quanzhou area, southeast of the Fujian province. The presence of the summer drought stress is because the peak temperature in July-August was accompanied by relatively low precipitation during this period. The high temperature, strong light, low precipitation, and thus low relative humidity in the summer months may lead to stomatal closure and an increase in evaporation from the soil. This increased evaporation causes a decrease in water supply for tree growth. In such conditions, a relatively low precipitation and, thus, a low relative humidity can be limiting factors for tree growth.

This study did not find any significant positive response to winter temperatures as observed in other studies in southeastern China(JIANPING DUAN et al., 2013). As our GM sampling site is not located at as high of an altitude as sites used by Chen et al.( Dan Chen et al., 2016), where the winter temperatures are too low to limit tree growth. These summer drought stressed growth patterns found in humid subtropical 
China are different from the drought stressed pattern in arid western China, where a significant and negative response to summer temperature was often the case(Feng Chen et al., 2012), as the warming-induced evapotranspiration in the arid region can be more stressful for vegetation growth than in the humid region with relatively abundant precipitation(Keyan Fang et al., 2015).

\subsection{Effects of sunshine and relative humidity on tree-ring $\Delta^{13} \mathrm{C}$}

In our study area, Cryptomeria fortunei tree-ring $\Delta^{13} \mathrm{C}$ had significant negative correlations with temperature during the second half of the year (from June 15 to November 05), and it had a significant positive correlation with sunshine hours from August 26 to September 30 (Fig. 4b). From early June, photosynthesis started to increase because of the relatively high amount of sunshine hours and the sufficient precipitation accumulated in the previous period(Lucas C. R. Silva et al., 2013). Under such conditions with enhanced photosynthesis, intensified consumption of the intercellular $\mathrm{CO}_{2}$ can be associated with reduced discrimination of the carbon isotope (Eq. 4)(Allison \& Francey, 1999; Max Berkelhammer et al., 2009). Meanwhile, the relatively high precipitation and relative humidity could increase the stomatal conductance and thus increase the supply of $C_{i}$ with more $\mathrm{CO}_{2}$, which could promote carbon isotope discrimination (Eq. 4). The high temperature associated enhancement of the evapotranspiration could reduce the stomatal conductance and thus the $C_{i}$, leading to reduced carbon isotope discrimination (Eq. 4). For such hot and humid climatic conditions in the GM study site, the temperature may be sufficient for 
373 photosynthesis, while the relative humidity can be insufficient because of the WPSH

374 (West Pacific Subtropical High)(Yong Hua et al., 2013). For example, previous

375 studies in Fujian Province, including Fang Guangyan $\left(25^{\circ} 53^{\prime} \mathrm{N}, 119^{\circ} 11^{\prime} \mathrm{E}\right)$ and Niu

376 Mulin $\left(25^{\circ} 26^{\prime} \mathrm{N}, 117^{\circ} 56^{\prime} \mathrm{E}\right)$, have also found that the tree-ring $\Delta^{13} \mathrm{C}$ was mainly

377 controlled by the low relative humidity and the high amount of sunshine hours from

378 July to September(Li et al., 2017; Xu et al., 2018).

\subsection{The iWUE $_{\text {mes }}$ and iWUE $_{\text {tra }}$ at the study sites}

On the annual scale, both iWUE $_{\text {mes }}$ and iWUE $_{\text {tra }}$ chronology show significant

382 et al., 2007).

et al., 2007). increasing trends at the study sites of GM (the slope for $\mathrm{iWUE}_{\text {mes }}$ being: $0.04, \mathrm{p}<$ 0.001; the slope for iWUE tra being: 0.08, $\mathrm{p}<0.001,1965-2017$ ) and NML (the slope for $\mathrm{iWUE}_{\text {mes }}$ being: $0.12, \mathrm{p}<0.001$; the slope for $\mathrm{iWUE}_{\text {tra }}$ being: $0.23, \mathrm{p}<0.001$, 1865-2014). During the past 100 years, the $\mathrm{CO}_{2}$ concentration in the atmosphere has

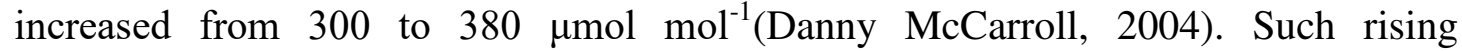
atmospheric $\mathrm{CO}_{2}$ concentration is affecting the gas-exchange metabolism of trees in several ways(KÖRNER et al., 2003). For instance, in controlled experiments, $\mathrm{CO}_{2}$ assimilation was generally stimulated and stomatal conductance was reduced by increased $\mathrm{CO}_{2}$ (C. PICON et al., 2010), suggesting that plants are able to increase their intrinsic water-use efficiency as $\mathrm{CO}_{2}$ levels rise(Bert G. Drake et al., 1997; Ceulemans 
394

395

On the intra-annual scale, the difference between $\mathrm{iWUE}_{\text {tra }}$ chronology and $\mathrm{iWUE}_{\mathrm{mes}}$ chronology is more apparent during the summer-autumn time (July 21-September 30) (Fig. 6). Analyzing the intra-annual time segment can provide higher resolution and higher rates of change for climate variables (such as temperature and light intensity), therefore reproducing more accurate climate variables in the environment where the trees grew at that time. Theoretically, under the drought limitation in summer and autumn (Fig. 2 and Fig. 6c), the stomata of Cryptomeria fortunei trees would close, resulting in the decrease of intercellular $\mathrm{CO}_{2}$ (Tei et al., 2014) concentrations, and finally leading to the increase of iWUE (Eq. 4). This was not the case in our study, as we observed an opposite trend for the iWUE $_{\text {mes }}$ value during July 21-September 30 (Fig. 6a). There are several possible reasons for this difference. First, $C_{a}$ dropped drastically, especially during July 21 to August 25, which will fundamentally change the $C_{i}$ of trees. Another reason is that, from July 21 to August 25, the maximum temperature (sunshine) and the insufficient precipitation increased evapotranspiration and exacerbated drought stress(Annika Hofgaard et al., 1999). Under drought stress, trees can respond by closing their stomata, which decreases stomatal conductance $\left(g_{w}\right)$ and increases iWUE. However, the drought-induced stoma will constrain the photosynthetic rate and lead to a reduction in carbohydrate synthesis (A) (Bert G. Drake et al., 1997; Norby et al., 2007; Wullschleger et al., 2010; Randerson et al., 2013). Eventually, the decline of the net photosynthetic rate (A) exceeded that of the stomatal conductance, resulting in the decline of iWUE in Cryptomeria fortunei trees. 


\section{Conclusions}

417 Based on the high-resolution $\delta^{13} \mathrm{C}$ of Cryptomeria fortunei tree-rings at the GM study 418 site, our analysis shows that the $\mathrm{iWUE}_{\text {mes }}$ model (Eq. 7) can be used to reasonably

419 estimate the intrinsic water use efficiency of trees. Our study suggests that both of the 420 iWUEs calculated from the two models ( $\mathrm{iWUE}_{\text {tra }}$ and $\mathrm{iWUE}_{\mathrm{mes}}$ ) show a significant 421 increasing trend, while the trend differs on inter-annual and intra-annual scales. On 422 the inter-annual scale, iWUE is overestimated by approximately 2 times, though this 423 overestimation has decreased in the past ten years. On the intra-annual scale, iWUE is

424 overestimated by an average of 2 times, and the degree of overestimation has decreased slightly during July 21 through August 25. The most distinct difference in iWUEs calculated using the two models ( $\mathrm{iWUE}_{\text {tra }}$ and $\mathrm{iWUE}_{\mathrm{mes}}$ ) appears in the summer-autumn time, when the $\mathrm{iWUE}_{\text {mes }}$ model indicates that the iWUE of trees has decreased significantly rather than increased. As our study shows, the iWUE $\mathrm{mes}_{\text {model }}$ can more effectively estimate iWUE without these levels of overestimation.

Acknowledgements: We acknowledge supports from the Strategic Priority Research Program of the Chinese Academy of Sciences (XDB26020000), the National Science Foundation of China (41822101, 41888101, 41971022 and 41772180), fellowship for the National Youth Talent Support Program of China (Ten Thousand People Plan), the Swedish Formas project (Future Research Leaders), the Swefellowship for Youth 
Talent Support Program of Fujian Province and the innovation team project (IRTL1705).

\section{References:}

Adams, M.A., Buckley, T.N., Turnbull, T.L., 2020. Diminishing $\mathrm{CO}_{2}$-driven gains in water-use efficiency of global forests. Nature Climate Change. 10, 466-471. https://doi.org/10.1038/s41558-020-0747-7.

Allison, C.E., Francey, R.J., 1999. $\delta^{13} \mathrm{C}$ of atmospheric $\mathrm{CO}_{2}$ at Cape Grim: the in situ record, the flask record, air standards and the CG92 calibration scale. Baseline Atmospheric Program.

Andrea Scartazza, F.P.V., Teresa Bertolini, Paul Di Tommasi, Marco Lauteri, Franco Miglietta, Enrico Brugnoli, 2014. Comparing integrated stable isotope and eddy covariance estimates of water-use efficiency on a Mediterranean successional sequence. Oecologia 176, 581-594. https://doi.org/10.1007/s00442-014-3027-2.

Annika Hofgaard, J.T., and Yves Bergeron, 1999. Dendroclimatic response of Picea mariana and Pinus banksiana along a latitudinal gradient in the eastern Canadian boreal forest. Canadian Journal of Forest Research. 29, 1333-1346. https://doi.org/10.1139/cjfr-29-9-1333.

Berry, U.S.A.R.H.G.J.A., 2008. Carbon isotopes and water use efficiency: sense and sensitivity. Oecologia. 155, 441-454. https://doi.org/10.1007/s00442-007-0932-7.

Bert G. Drake, M.A.G.-M., Steve P. Long, 1997. MORE EFFICIENT PLANTS: A Consequence of Rising Atmospheric $\mathrm{CO}_{2}$ ? Annual Review of Plant Physiology and 
461

462

463

464

465

466

467

468

469

470

471

472

473

474

475

476 477 composition of oxygen in atmospheric $\mathrm{CO}_{2}$. Nature. 363, 439-443.

478 https://doi.org/10.1038/363439a0.

479 Feng Chen, Y.Y., Wenshou Wei, Lily Wang, Shulong Yu, Ruibo Zhang, Ziang Fan, 480

https://doi.org/10.1146/annurev.arplant.48.1.609.

C. PICON, J.M.G., A. FERHI, 2010. Leaf gas exchange and carbon isotope composition responses to drought in a drought-avoiding (Pinus pinaster) and a drought-tolerant (Quercus petraea) species under present and elevated atmospheric CO2 concentrations. Plant, Cell and Environment. 19, 182-190. https://doi.org/ 10.1111/j.1365-3040.1996.tb00239.x.

R Ceulemans, B Gielen, ME Jach, IA Janssens, 2007. Global carbon: of pools and fluxes, or standing stocks and cycling rates. Topics in Ecology Structure Function in Plants Ecosystems. http://hdl.handle.net/1942/6937.

CHEN Dan, F.K., LI YingJun, DONG ZhiPeng, ZHANG Yu, ZHOU FeiFei, 2016. Response of Pinus taiwanensis growth to climate changes at its southern limit of Daiyun Mountain, mainland China Fujian Province. Science China Earth Sciences. 59 (2), 328-336. https://doi.org/10.1007/s11430-015-5188-1.

Danny McCarroll, N.J.L., 2004. Stable isotopes in tree rings. Quaternary Science Reviews. 23, 771-801. https://doi.org/10.1016/j.quascirev.2003.06.017.

Ehleringer, G.F.J.L.J.T.L.F.J.S.K.H.S.W.J., 1993. Vegetation effects on the isotope Huaming Shang, Tongwen Zhang, Yang Lia, 2012. Tree ring density-based summer 
481

482

483

484

485

486

487

488

489

490

491

492

493

494

495

496

497

498

499

500

501

temperature reconstruction for Zajsan Lake area, East Kazakhstan. International Journal of Climatology. 32, 1089-1097. https://doi.org/10.1002/joc.2327.

Franks, PJ, Adams, MA, Amthor, JS, Barbour, MM, Berry, JA, Ellsworth, DS, Farquhar, GD, Ghannoum, Lloyd, McDowell, Norby, RJ, Tissue, DT, von, Caemmerer, 2013. Sensitivity of plants to changing atmospheric $\mathrm{CO}_{2}$ concentration: from the geological past to the next century. New Phytologist. 197, 1077-1094. https://doi.org/10.1111/nph.12104.

G, D, Farquhar, J, R, Ehleringer, K, T, Hubick, 1989. Carbon Isotope Discrimination and Photosynthesis. Annual Review of Plant Biology. 40, 503-537. https://doi.org/ 10.1146/annurev.pp.40.060189.002443.

I. C. Prentice, S.P.H., 2009. Ecosystem effects of $\mathrm{CO}_{2}$ concentration: evidence from past climates. Climate of the Past. 5, 297-307. https://doi.org/10.5194/cpd-5-937-2009.

INÊS C. R. BARBOSA, I.H.K., KARL AUERSWALD, PETER LÜPS, HANS SCHNYDER, 2010. Last-century changes of alpine grassland water-use efficiency: a reconstruction through carbon isotope analysis of a time-series of Capra ibex horns.
Global
Change
Biology.
16
$1171-1180$.

https://doi.org/10.1111/j.1365-2486.2009.02018.x.

JAMES R. EHLERINGER, T.E.C., 1995. Atmospheric $\mathrm{CO}_{2}$ and the ratio of intercellular to ambient CO2 concentration in plants. Tree Physiology. 15, 105-111. https://doi.org/10.1111/10.1093/treephys/15.2.105. 
502

503

504

505

506

507

508

509

510

511

512

513

514

515

516

517

518 519 https://doi.org/10.1139/x93-028.

520 Leavitt, S.W., 2008. Tree-ring isotopic pooling without regard to mass: No difference 521 from averaging delta C-13 values of each tree. Chemical Geology. 252, 52-55.

522

Jian-Guo Huang, Y.B., Bernhard Denneler, Frank Berninger, Jacques Tardif, 2007.

Response of forest trees to increased atmospheric $\mathrm{CO}_{2}$. Critical Reviews in Plant

Sciences. 26, 265-283. https://doi.org/10.1080/07352680701626978.

JIANPING DUAN, Q.-B.Z., AND LI-XIN LV, 2013. Increased Variability in Cold-Season Temperature since the 1930s in Subtropical China. Journal of Climate. 26, 4749-4757. https://doi.org/10.1175/JCLI-D-12-00332.1.

Keyan Fang, D.F., Yan Zhao, Feifei Zhou, Heikki Seppä, 2015. Moisture stress of a hydrological year on tree growth in the Tibetan Plateau and surroundings. Environmental Research

Letters.

10,

034010.

https://doi.org/10.1088/1748-9326/10/3/034010.

KÖRNER, C., 2003. Carbon limitation in trees. Journal of Ecology. 91, 4-17. https://doi.org/10.1046/j.1365-2745.2003.00742.x.

Leavitt, GEOL, S.J.C., 2008. Tree-ring isotopic pooling without regard to mass: No difference from averaging delta $\mathrm{C}-13$ values of each tree. Chemical Geology. 252(1-2), 52-55. https://doi.org/10.1016/j.chemgeo.2008.01.014.

Leavitt, S., 1993. Seasonal ${ }^{13} \mathrm{C} /{ }^{12} \mathrm{C}$ changes in tree rings: species and site coherence, and a possible drought influence. Canadian Journal of Forest Research. 23, 210-218. https://doi.org/10.1016/j.chemgeo.2008.01.014. 
523

524

525

526

527

528

529

530

531

532

533

534

535

536

537

538

539

540

541

542

543

Dawen Li, Keyan Fang, Yingjun Li, Deliang Chen, Yanping Li, 2017. Climate, intrinsic water-use efficiency and tree growth over the past 150 years in humid subtropical China.

Plos

One.

12 ,

e0172045. https://doi.org/10.1371/journal.pone.0172045.

LIU XiaoHong, S.X., WANG LiLi, ZHAO LiangJu, WU Pu, CHEN Tuo, QIN DaHe, REN JiaWen, 2007. Climatic significance of the stable carbon isotope composition of tree-ring cellulose:Comparison of Chinese hemlock (Tsuga chinensis Pritz) and alpine pine (Pinus densata Mast) in a temperate-moist region of China. Science in China Series D: Earth Sciences. 50, 1076-1085. https://doi.org/10.1007/s11430-007-0043-7. Lucas C. R. Silva, A.M., 2013. Probing for the influence of atmospheric $\mathrm{CO}_{2}$ and climate change on forest ecosystems across biomes. Global Ecology and Biogeography. 22, 83-92. https://doi.org/10.1111/j.1466-8238.2012.00783.x.

Max Berkelhammer, L.D.S., 2009. Modeled and observed intra-ring $\delta^{18} \mathrm{O}$ cycles within late Holocene Bristlecone Pine tree samples. Chemical Geology. 264, 0-23. https://doi.org/10.1016/j.chemgeo.2009.02.010.

WK Soh, C Yiotis, MMN Murray, AC Parnell, JC Mcelwain, 2019. Rising $\mathrm{CO}_{2}$ drives divergence in water use efficiency of evergreen and deciduous plants. Science Advances. 5, eaax7906. https://doi.org/10.1126/sciadv.aax7906.

J Flexas, M Ribas-Carbó, A Diaz-Espejo, J Galmés, H Medrano, 2010. Mesophyll conductance to $\mathrm{CO}_{2}$ : current knowledge and future prospects. Plant, Cell and Environment. 31, 602-621. https://doi.org/10.1111/j.1365-3040.2007.01757.x. 
544

545

546

547

548

549

550

551

552

553

554

555

556

557

558

559

560

561

562

563

564

565

Millicent Smith, B.W., Andreas Richter, Kevin Simonin, Andrew Merchant, 2016.

Carbon Isotope Composition of Carbohydrates and Polyols in Leaf and Phloem Sap of

Phaseolus vulgaris L. Influences Predictions of Plant Water Use Efficiency. Plant and Cell Physiology. 1756. https://doi.org/10.1093/pcp/pcw099.

Christian Krner, J Morgan, R Norby, 2007. $\mathrm{CO}_{2}$ Fertilization: When, Where, How Much? Terrestrial Ecosystems in a Changing World. 9-21. https://doi.org/10.1007/978-3-540-32730-1_2.

Pei Li Fu, J.G., Aster Gebrekirstos, Ze-Xin Fan, Achim Bräuning, 2016. Earlywood and Latewood Stable Carbon and Oxygen Isotope Variations in Two Pine Species in Southwestern China during the Recent Decades. Frontiers in Plant Science. 7, 2050. https://doi.org/10.3389/fpls.2016.02050.

Nate McDowell, Dennis Baldocchi, Margaret Barbour, Chris Bickford, Matthias Cuntz, Dave Hanson, Alexander Knohl, Heath Powers, Thomas Rahn, Jim Randerson, 2013. Understanding the Stable Isotope Composition of Biosphere-Atmosphere $\mathrm{CO}_{2}$ Exchange. Eos Transactions American Geophysical Union. 89, 94-95. https://doi.org/10.1029/2008EO100002.

Iris H. Khler, Andy Macdonald, Hans Schnyder, 2012. Nutrient supply enhanced the increase in intrinsic water-use efficiency of a temperate seminatural grassland in the last century. Global Change Biology. 18, 3367-3376. https://doi.org/10.1111/j.1365-2486.2012.02781.x.

Matthias Saurer, Rolf T. W. Siegwolf, Fritz H. Schweingruber, 2004. Carbon isotope discrimination indicates improving water-use efficiency of trees in northern Eurasia 
566

567

568

569

570

571

572

573

574

575

576

577

578

579

580

581

582

583

584

585

586

587

over the last 100 years. Global Change Biology. 10, 2109-2120. https://doi.org/10.1111/j.1365-2486.2004.00869.x.

Stokes, M.A., Smiley, 1968. An Introduction to Tree-Ring Dating. Nature. 268 (5619), 402-404.

Shunsuke Tei, Atsuko Sugimoto, Hitoshi Yonenobu, Takeshi Ohta, Trofim C.

Maximov, 2014. Growth and physiological responses of larch trees to climate changes deduced from tree-ring widths and $\delta^{13} \mathrm{C}$ at two forest sites in eastern Siberia. Polar Science. 8(2), 183-195. https://doi.org/10.1016/j.polar.2013.12.002.

Todd E. Dawson, S.M., Agneta H. Plamboeck, Pamela H. Templer, Kevin P. Tu, 2002. Stable Isotopes in Plant Ecology. Annual Review of Ecology and Systematics. 33, 507-559. https://doi.org/10.1146/annurev.ecolsys.33.020602.095451.

Wei Ting Ma, G.T., Xu Ming Wang, Rudi Schäufele, Hans Schnyder, Yusheng Yang, Xiao Ying Gong, 2020. Revisiting the carbon isotope discrimination and water use efficiency relation: the influence of mesophyll conductance.

S. D. WULLSCHLEGER, T. J. TSCHAPLINSKI, R. J. NORBY, 2010. Plant water relations at elevated $\mathrm{CO}_{2}$-implications for water-limited environments. Plant, Cell and Environment. 25, 319-331. https://doi.org/10.1046/j.1365-3040.2002.00796.x.

Xiaohong Liu, W.W., Guobao Xu, Xiaomin Zeng, Guoju Wu, Xuanwen Zhang, Dahe Qin, 2014. Tree growth and intrinsic water-use efficiency of inland riparian forests in northwestern China: evaluation via $\delta^{13} \mathrm{C}$ and $\delta^{18} \mathrm{O}$ analysis of tree rings. Tree Physiology. 34, 966-980. https://doi.org/10.1093/treephys/tpu067.

Guobao Xu, Xiaohong Liu, Soumaya Belmecheri, Tuo Chen, Guoju Wu, Bo Wang, 
588

589

590

591

592

593

594

595

596

597

598

599

600

601

602

603

604

605

606

607

608

Xiaomin Zeng, Wenzhi Wang, 2018. Disentangling Contributions of $\mathrm{CO}_{2}$

Concentration and Climate to Changes in Intrinsic Water-Use Efficiency in the Arid

Boreal Forest in China's Altay Mountains. Forests. 9 (10), 642. https://doi.org/10.3390/f9100642.

Yingjun Li, Zhipeng Dong, Deliang Chen, Siyuan Zhao, Feifei Zhou, Xinguang Cao, Keyan Fang, 2019. Growth decline of Pinus Massoniana in response to warming induced drought and increasing intrinsic water use efficiency in humid subtropical

China.

Dendrochronologia.

57

125609.

https://doi.org/10.1016/j.dendro.2019.125609.

LI Yong Hua, Q Ji Ming, LI Qiang, 2013. Features of Western Pacific Subtropical High (WPSH) Associated with Drought/Flood in Summer over the Eastern Part of Southwest China. Journal of Southwest University.

Zhang, Lina, Wang, Bizheng, Zeng, 2009. Impact of the Madden-Julian Oscillation on Summer Rainfall in Southeast China. Journal of Climate. 22, 201-216. https://doi.org/10.1175/2008JCLI1959.1.

Zsofa R. Stangl, Lasse Tarvainen, Göran Wallin, Nerea Ubierna, Mats Räntfors, John D. Marshall, 2019. Diurnal variation in mesophyll conductance and its influence on modelled water-use efficiency in a mature boreal Pinus sylvestris stand. Photosynthesis Research. 141. https://doi.org/10.1007/s11120-019-00645-6.

Peter van der Sleen, Peter Groenendijk, Mart Vlam, Niels P. R. Anten, Arnoud Boom, Frans Bongers, Thijs L. Pons, Gideon Terburg, Pieter A. Zuidema, 2015. No growth 
609

610

611

612

613

614

615

616

617

618

619

620

621

622

623

624

625

626

627

628

629

630

stimulation of tropical trees by 150 years of $\mathrm{CO}_{2}$ fertilization but water-use efficiency increased. Nature Geoscience. 8, 24-28. https://doi.org/10.1038/ngeo2313.

Figure captions

Fig. 1. Location of the tree-ring sampling site and the meteorological station.

Fig. 2. Correlations between climate variables and the tree-ring standard chronology (STD) for the period of 1965-2017. The blue (black) horizontal lines represent the $95 \%(99 \%)$ confidence level.

Fig. 3. (a) The ratio of tree-ring stable carbon isotope of Cryptomeria fortunei and the ratio of atmospheric stable carbon isotope from 1965 to 2017 at GM and (b) the discrimination of tree-ring stable carbon isotope from 1965 to 2017.

Fig. 4. The Pearson correlation between the intra-annual tree-ring $\Delta^{13} \mathrm{C}$ and the climatic variables (average temperature, average precipitation, average relative humidity and average sunshine hours) from 1965 to 2017 at the study site. The black (red) horizontal dash lines represent the 95\% (99\%) confidence level.

Fig. 5. Intra-annual (a) and (b) annual chronology of $i W U E_{m e s}$ and $i W U E_{\text {tra }}$ at the 
631

632

633

634

635

636

637

638

639

640

641

642

643

644

645

646

647

648

649

650

651

652

study sites.

Fig. 6. Intra-annual iWUE (iWUE $E_{\text {mes }}$ and $\mathrm{iWUE}_{\text {tra }}$ ) (a), atmospheric $\mathrm{CO}_{2}$ concentration $\left(C_{a}\right)$ and intercellular $\mathrm{CO}_{2}$ concentrations (Tei et al.) inferred from iWUE tra and iWUE $_{\text {mes }}$ (b) and climate variables(c) at GM study site for the period of 1965-2017.

Fig. 7. Relative importance of climate variables to the intra-annual iWUE chronologies (iWUE mes $_{\text {and }}$ iWUE $_{\text {tra }}$ ) during the period 1965-2017 based on the Package relaimpo in $\mathrm{R}$. The red numbers represent relative importance, which ranges from 0 to 1 .

Table 1. Dates of the 10 sub-samples each ring at GM study site.

(1) 


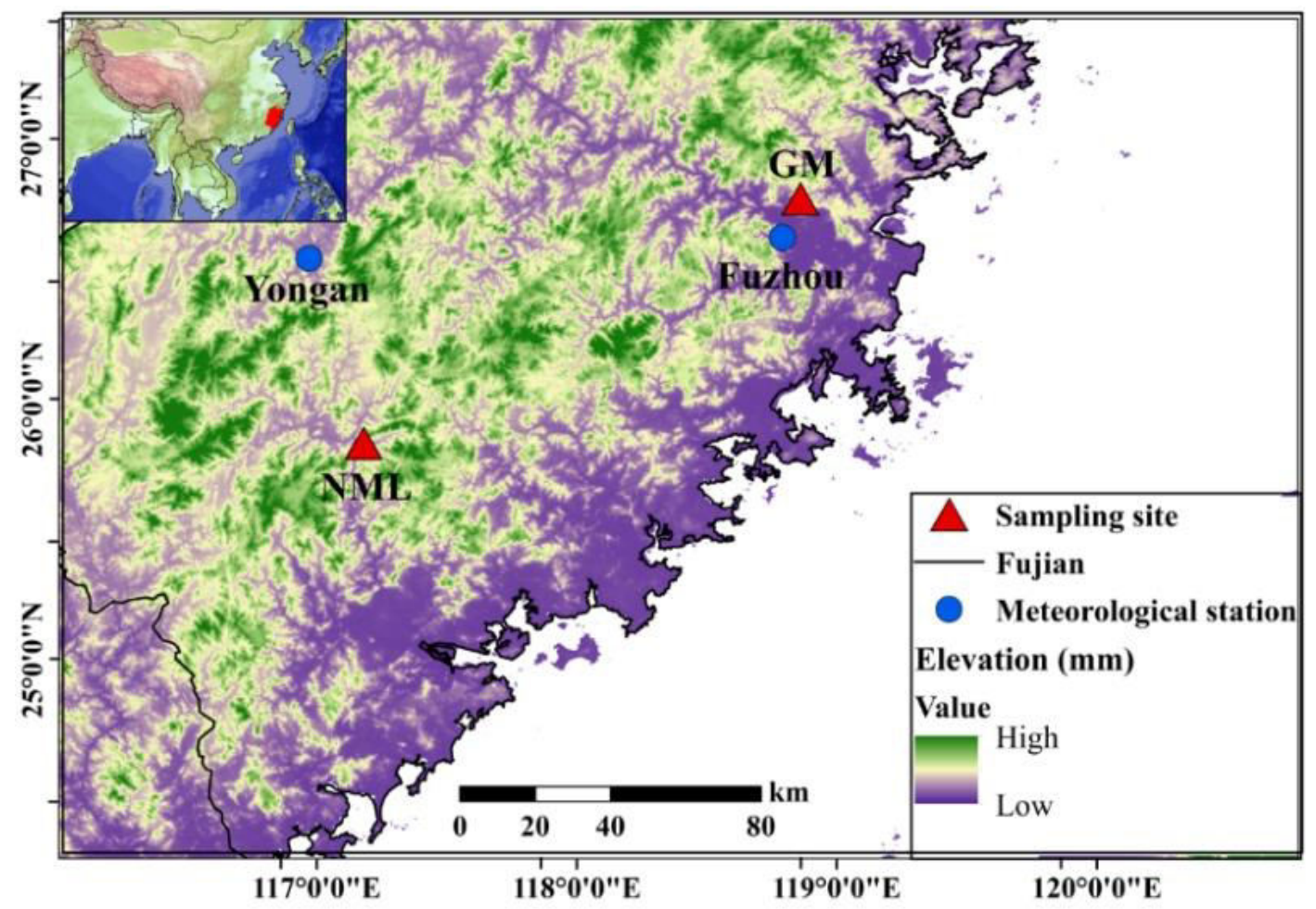

655

656

Fig. 1.

657

658

659

660

661

662

663

664

665

666 


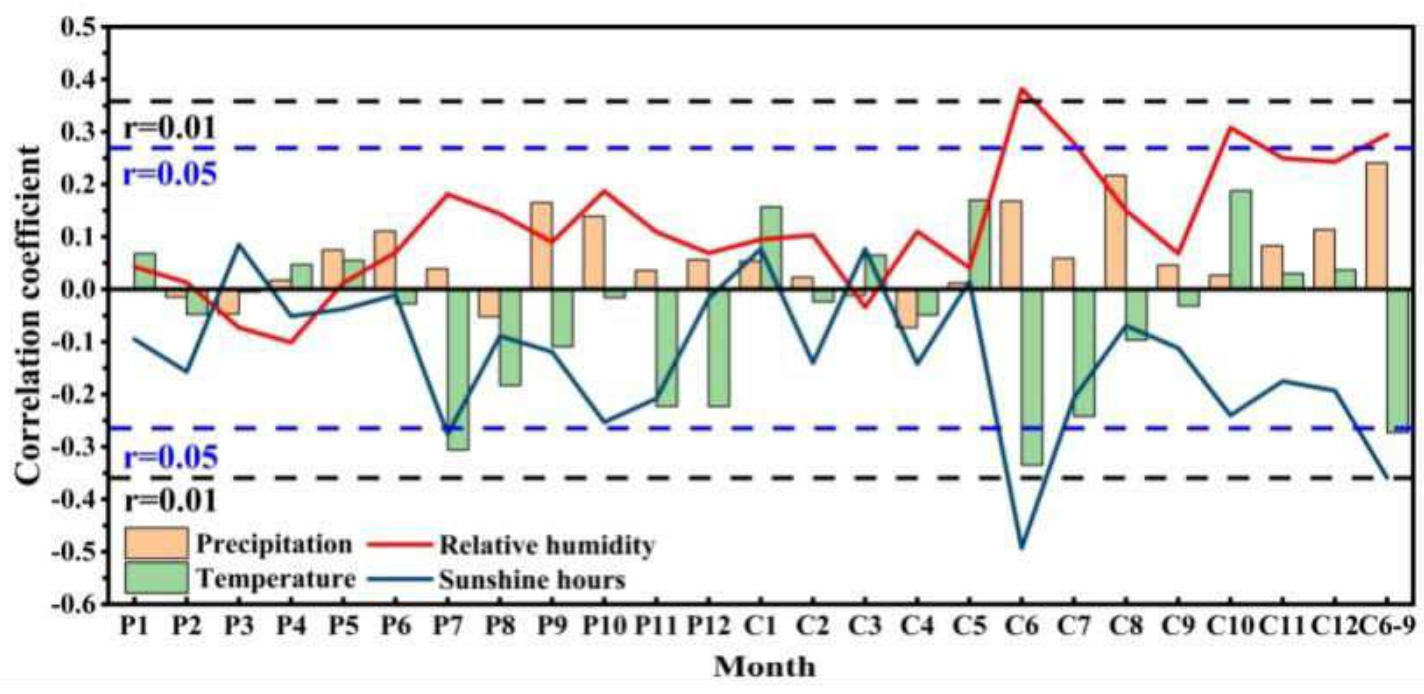

Fig. 2

671

672

673

674

675

676

677

678

679

680

681

682 

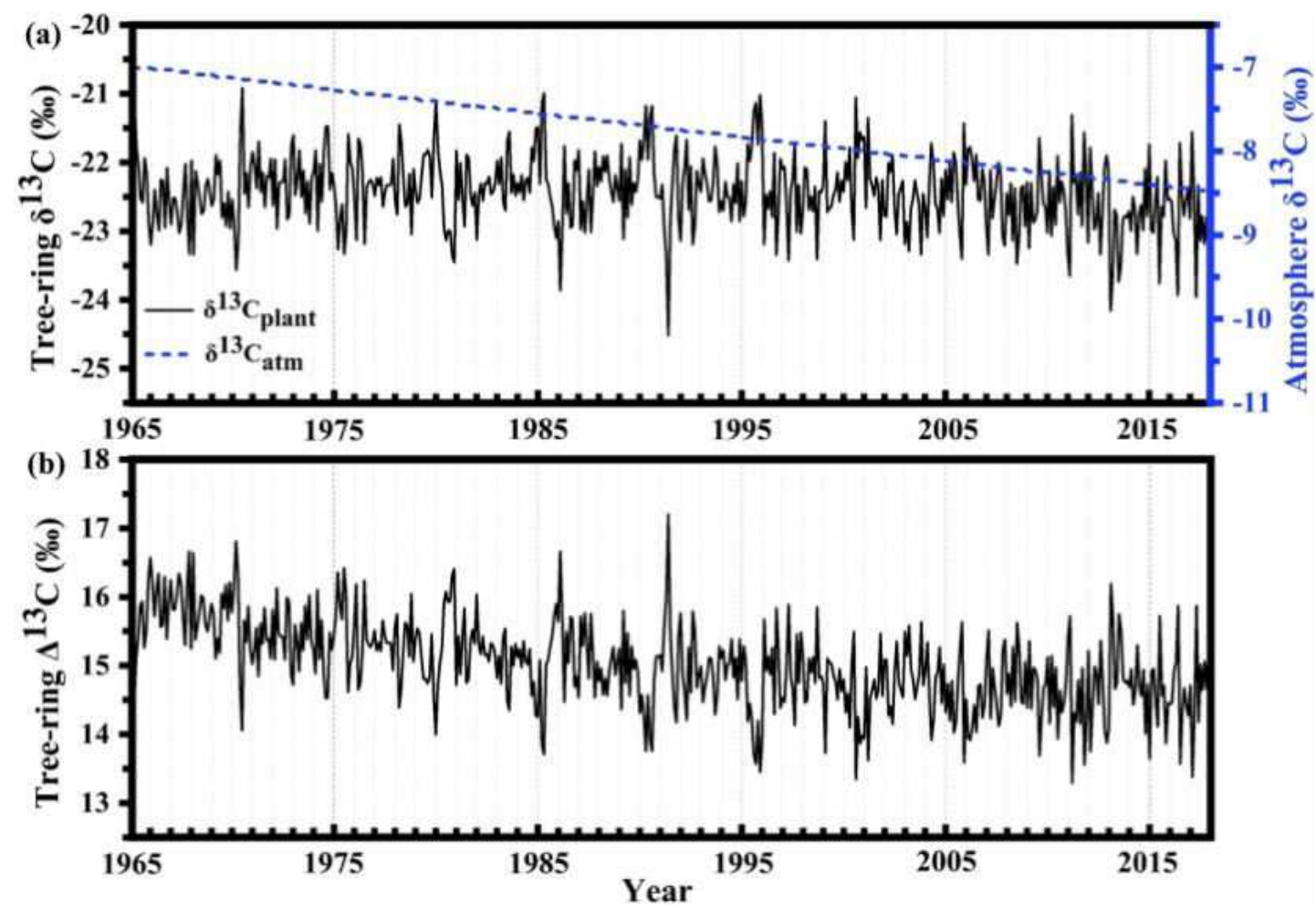

686

687

Fig. 3.

688

689

690

691

692

693

694

695

696

697 


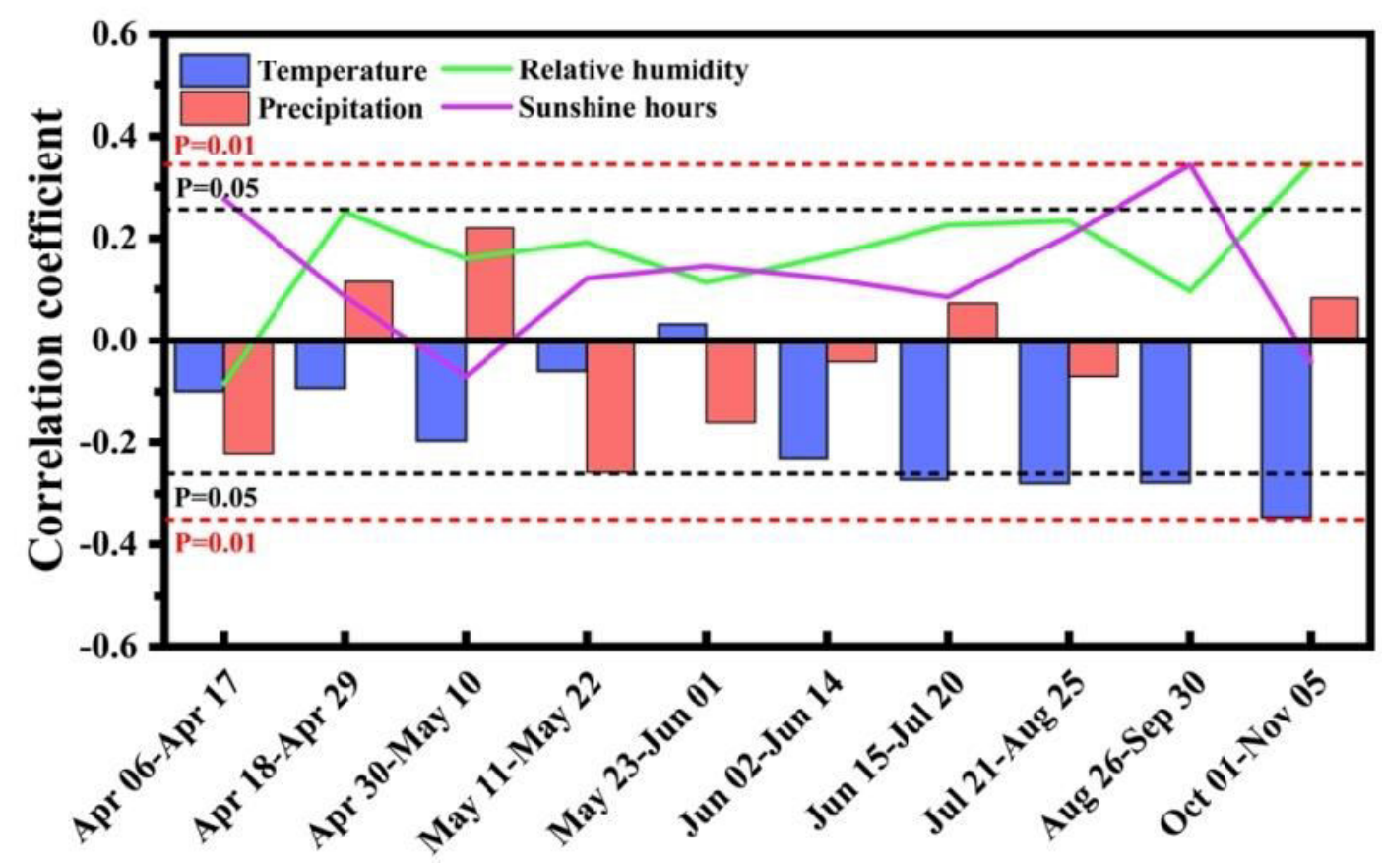

Fig. 4. 

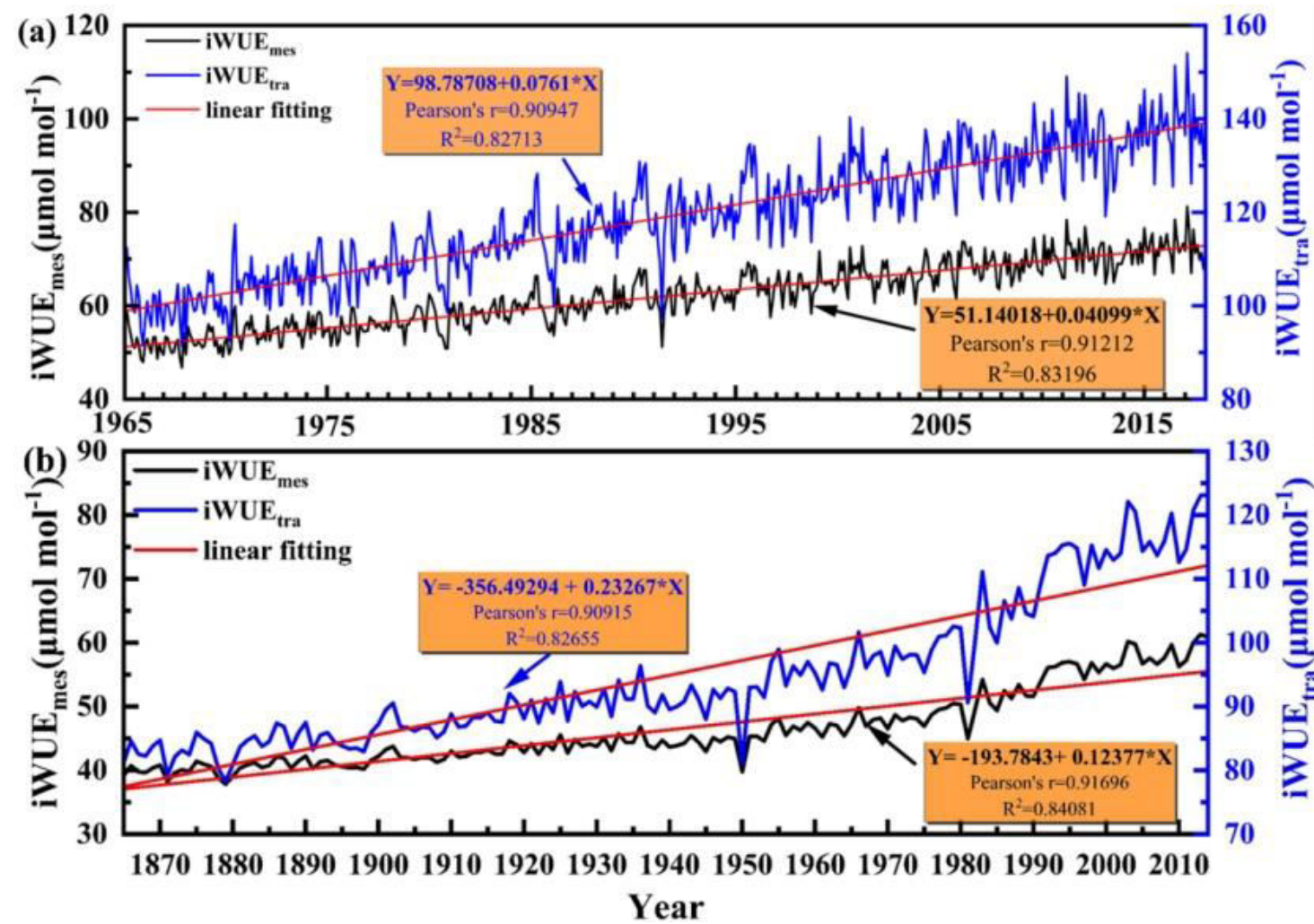

Fig. 5 


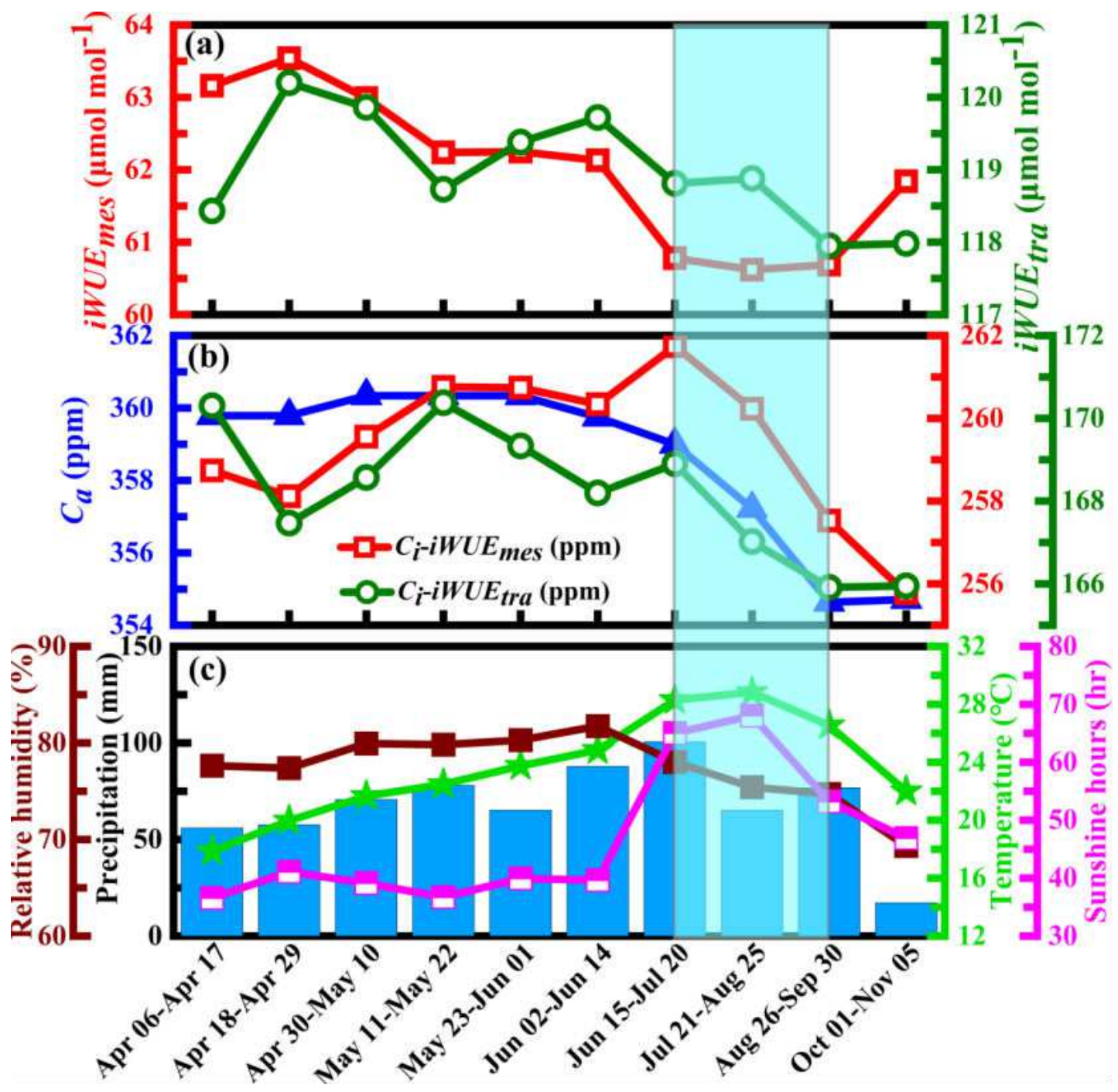

Fig. 6 


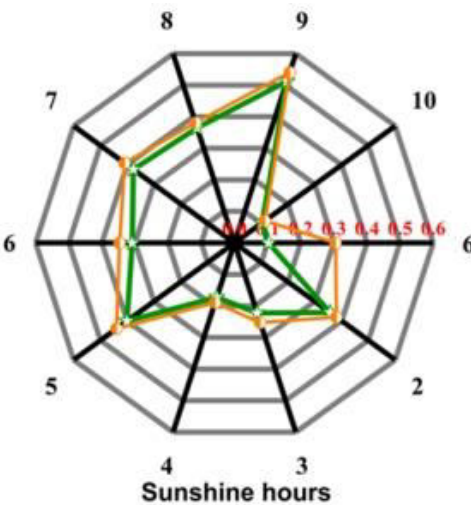

shine hours

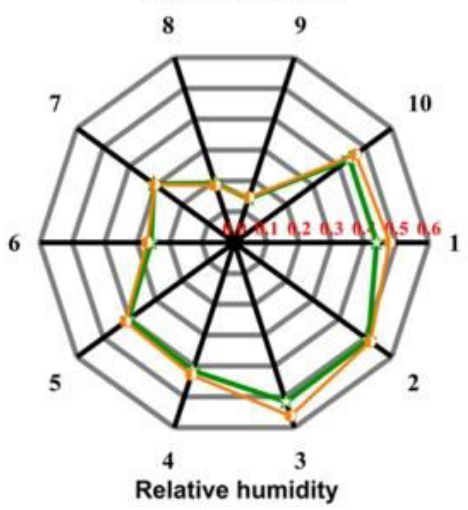

739

740

741

742

743

744

745

746

747

748

749

750

\section{Fig. 7}

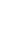

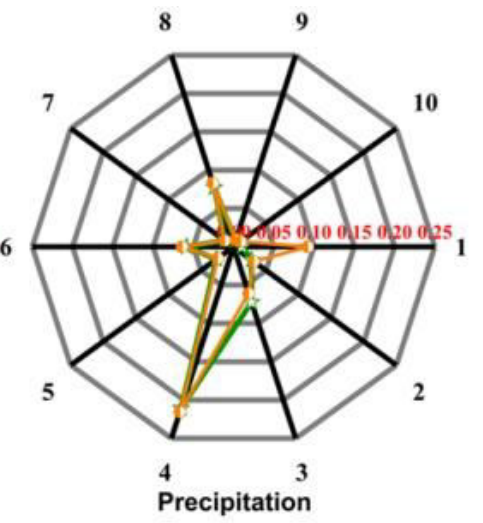

$8 \quad 9$

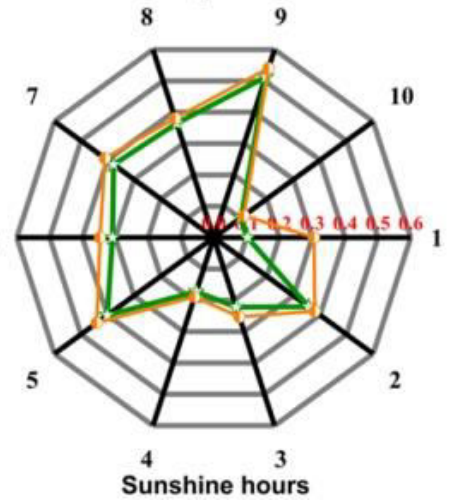

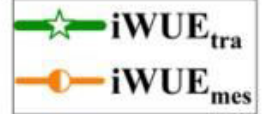

1: April 06-April 17

2: April 18-April 29

3: April 30-May 10

4: May 11-May 22

5: May 23-June 01

6: June 02-June 14

7: June 15-July 20

8: July 21-August 25

9: August 26-September 30

10: October 01-November 05 
751

\begin{tabular}{llll}
\hline Number of & & Number of & \\
sub-sample & Date of each number & \multicolumn{2}{l}{ Date of each number } \\
\hline 1 & Apr 06-Apr 17 & 6 & Jun 02-Jun 14 \\
\hline 2 & Apr 18-Apr 29 & 7 & Jun 15-Jul 20 \\
3 & Apr 30-May 10 & 8 & Jul 21-Aug 25 \\
4 & May 11-May 22 & 9 & Aug 26-Sep 30 \\
5 & May 23-Jun 01 & 10 & Oct 01-Nov 05 \\
\hline
\end{tabular}

752

753 Table 1.

754

755 


\section{Supplementary Files}

This is a list of supplementary files associated with this preprint. Click to download.

- Supplementarylnformation.doc 